cross-sectional study and, although, for purposes of understanding, we presented the results in terms of the mean values of individual contributing variables, the cluster technique uses a multivariable distance measure in nine dimensions; thus, the associations between the contributing variables may be more complex than this. Apart from determining the natural history of these clusters in our cohort study, other forms of external validation, such as developing a clinical allocation rule and determining the response of different phenotypes to therapy, will also contribute understanding to the different phenotypes of chronic obstructive pulmonary disease.

\author{
M. Weatherall*, J. Travers", P. Shirtcliffe", S. Marsh", M. \\ Williams", M. Nowtiz ${ }^{\#}$ S. Aldington" and R. Beasley ${ }^{\#}$ \\ *Dept of Medicine, University of Otago, and "Medical Research \\ Institute of New Zealand, Wellington, New Zealand.
}

Correspondence: $\mathrm{M}$. Weatherall, Dept of Medicine, University of Otago, PB 7343, Wellington South, 6242, Wellington, New Zealand. E-mail: mark.weatherall@otago.ac.nz

Statement of Interest: None declared.

\section{REFERENCES}

1 Weatherall M, Travers J, Shirtcliffe $\mathrm{P}$, et al. Distinct clinical phenotypes of airways disease defined by cluster analysis. Eur Respir J 2009; 34: 812-818.

2 Wardlaw AJ, Silverman M, Siva R, et al. Multi-dimensional phenotyping: towards a new taxonomy for airway disease. Clin Exp Allergy 2005; 35: 1254-1262.

3 Haldar P, Pavord ID, Shaw DE, et al. Cluster analysis and clinical asthma phenotypes. Am J Respir Crit Care Med 2008; 178: 218-224.

DOI: 10.1183/09031936.00167309

\title{
The Achilles heel of endothelin receptor therapy for pulmonary arterial hypertension
}

\section{To the Editors:}

We were interested to read the letter from LAVELLE et al. [1], together with the accompanying editorial [2], regarding liver toxicity in patients receiving endothelin receptor antagonist therapy (ERA) for pulmonary arterial hypertension. Both of these articles highlight the potential for severe liver toxicity in patients receiving sitaxentan and stress the continued need for regular monitoring of liver function tests in all patients receiving ERAs. In fact, the details of the reported cases show that severe liver toxicity can occur within the time period of a month and one of us (P.A. Corris) has experience of a further case of fulminant hepatic failure occurring on treatment with sitaxentan when the liver function tests were normal less than one month beforehand. This suggests that all patients and the patients' relatives should be advised to report any symptoms or signs of hepatic disease, such as anorexia, abdominal pain or jaundice as soon as they are noticed.

We disagree with the suggestion that, based on current data, sitaxentan may be afflicted with a higher potential to severe liver toxicity. Severe toxicity has also been reported with bosentan, with or without other potential medication interactions.

NAGAi et al. [3] reported multi organ failure following severe hepatitis (AST and ALT levels >5000 IU) in a patient receiving bosentan. That patient died. DWYER et al. [4] reported severe toxicity with the combination of bosentan and methotrexate, which did not recur on the presence of methotrexate alone. One of us (P.A. Corris) has recently diagnosed a case of severe liver toxicity due to hypersensitivity reaction to ambrisentan. HUMBERT et al. [5] reported on nine patients satisfying Hy's law for severe liver toxicity due to bosentan therapy on the TRAX safety database, though no clinical details were reported. About $20 \%$ of patients treated with bosentan in Europe were not entered into that database, so there may have been more cases. Under-reporting of all medication-related complications is a chronic health care issue.

In summary, physicians should be aware that severe hepatic toxicity may be seen in patients receiving any of the current ERA therapies, and that there may be interactions with other potentially hepatotoxic medications. Patients must be advised to consult their prescribing physician urgently on the first signs and symptoms of hepatic toxicity, irrespective of normal liver function tests within a month earlier. Every case of severe hepatotoxicity should be reported. Knowing the true degree of vulnerability of this particular "Achilles' heel" will allow for better scientific conclusions.

\section{P.A. Corris* and D. Langleben ${ }^{\#}$}

*Institute of Cellular Medicine Newcastle University and Cardiothoracic Centre Freeman Hospital Newcastle, UK. \#Center for Pulmonary Vascular Disease, Jewish General Hospital, Montreal, QC, Canada.

Correspondence: P.A. Corris, Institute of Cellular Medicine Newcastle University and Cardiothoracic Centre, Freeman Hospital, Newcastle NE7 7DN, UK. E-mail: paul.corris@ncl.ac.uk

Statement of Interest: Statements of interest for both authors of this manuscript can be found at www.erj.ersjournals.com/misc/ statements.dtl 


\section{REFERENCES}

1 Lavelle A, Sugrue R, Lawler G, et al. Sitaxentan-induced hepatic failure in two patients with pulmonary arterial hypertension. Eur Respir J 2009; 34: 770-775.

2 Hoeper MM. Liver toxicity: the Achilles heel of endothelin receptor antagonist therapy? Eur Respir J 2009; 34: 529-530.

3 Nagai Y, Okada E, Mihara S, et al. Severe liver dysfunction due to bosentan in a patient with mixed connective tissue disease. Eur J Dermatology 2008; 18: 190-191.

4 Dwyer N, Jones G, Kilpatrick D. Severe hepatotoxicity in a patient on bosentan upon addition of methotrexate. J Clin Rheumatology 2009; 15: 88-89.

5 Humbert M, Segal ES, Kiely DG, et al. Results of European postmarketing surveillance of bosentan in pulmonary hypertension. Eur Respir J 2007; 30: 338-344.

DOI: $10.1183 / 09031936.00160309$

\section{From the author:}

I thank P.A. Corris and D. Langleben for their comments on my editorial [1] in which I have clearly indicated that: "...the possibility cannot be excluded that sitaxentan is afflicted with a higher potential of causing severe liver toxicity than the two other ERAs. As exact numbers are not available, and underreporting may have occurred for any of the three drugs, there is not enough evidence to decide whether this conclusion is justified." This statement clearly is in line with the comments of P.A. Corris and D. Langleben who should be applauded for alerting us about further cases of severe liver toxicity associated with the use of all three endothelin receptor antagonists, some of which have not been reported in the medical literature. The statement of P.A. Corris and D. Langleben that "every case of severe hepatotoxicity should be reported" does not seem to differ from the final conclusion of my editorial that "...liver monitoring should remain an integral part of ERA therapy. Physicians are urged to report all cases of serious liver injury potentially linked to these drugs..." This remains true for all three endothelin receptor antagonists.

\section{M.M. Hoeper}

Respiratory Medicine, Hannover Medical School, Hannover, Germany.

Correspondence: M.M. Hoeper, Respiratory Medicine, Hannover Medical School, Carl-Neuberg-Str. 1, Hannover, Germany. E-mail: hoeper.marius@mh-hannover.de

Statement of Interest: A statement of interest for M.M. Hoeper can be found at www.erj.ersjournals.com $/ \mathrm{misc} /$ statements.dtl

\section{REFERENCES}

1 Hoeper MM. Liver toxicity: the Achilles' heel of endothelin receptor antagonist therapy? Eur Respir J 2009; 34: 529-530.

DOI: 10.1183/09031936.00166409 